\title{
Erratum to: Connectivity between electron transport complexes and modulation of photosystem II activity in chloroplasts
}

\author{
Alexander N. Tikhonov $^{1}$ - Alexey V. Vershubskii ${ }^{1}$
}

Published online: 18 May 2017

(C) Springer Science+Business Media Dordrecht 2017

\section{Erratum to: Photosynth Res}

DOI 10.1007/s11120-017-0349-z

The figure panels in Fig. 5 were incorrectly labelled in the initial online publication. The original article has been corrected.

The online version of the original article can be found under doi:10.1007/s11120-017-0349-z.

$\triangle$ Alexander N. Tikhonov

an_tikhonov@mail.ru; an_tikhonov@physics.msu.ru

1 Faculty of Physics, Moscow State University, Moscow, Russia 119991 